\title{
Tatyana Yakhontova*
}

Ivan Franko National University of Lviv, Ukraine

tetyana.yakhontova@lnu.edu.ua

\section{E.SPP.Today

\section{Oryslava Ivantsiv}

Ternopil Volodymyr Hnatiuk National Pedagogical University, Ukraine ivantsiv.o@tnpu.edu.ua

\section{"WE ARE STRONG BELIEVERS IN THE POWER OF THE AVON BRAND": GENRE FEATURES OF INTERNATIONAL COSMETICS COMPANIES' E-RELEASES}

\section{Abstract}

Press releases have traditionally been defined as short, written texts sent to the news media by companies with a global aim of accumulating publicity capital and developing a positive corporate image. With the advent of the Internet, press releases have increasingly been posted on corporate websites, appearing as separate webpages in the companies' virtual newsrooms. In this article, the overall format, move structures, prominent linguistic features, and novel functional characteristics of cosmetic companies' electronic press releases are examined. The study is based on a two-stage procedure of analysis which reflects a bidimensional vision of Internet genres, as both media and texts. As the results show, e-releases generally preserve the organization typical of the press release genre, while at the same time displaying some new features, such as two additional moves and the use of self-evaluative, highly promotional, and sometimes even poetic language. Digital functionality is utilized differently by cosmetics companies, depending on how they use e-releases to promote their corporate image. The findings of the study can help to enhance and enrich university courses in public relations and business communications.

\section{Key words}

e-release, press release, Internet genre, move structure, linguistic features, promotional style.

\footnotetext{
* Corresponding address: Tatyana Yakhontova, Department of Foreign Languages for Natural Sciences, Ivan Franko National University of Lviv, 41, Doroshenka Street, Lviv, Ukraine.
} 


\section{INTRODUCTION}

Press releases have traditionally been defined as short, written texts sent to the news media by companies, government agencies, political parties or non-profit institutions to share information with the public about new developments in those organizations (Jacobs, 2014: 583). With the advent of the Internet, press releases have increasingly been posted on corporate websites, appearing as separate webpages in the companies' virtual newsrooms. Nowadays, electronic press releases (henceforth ereleases) are widely spread by online distribution services (e.g. Business Wire, https://www.businesswire.com or PRWeb, https://service.prweb.com), which help to effectively disseminate business news. Furthermore, e-releases are indexed by search engines, and thus each of them becomes "a permanent record" which can be accessed and read many years after its actual appearance (Thaeler, 2009: 10).

New technologies have modified the communicative functions of traditional press releases. For example, one study (Vorvoreanu, 2008) has shown that ereleases as communication tools have begun to be used not only by public relations specialists but also by representatives of the marketing profession. Consequently, e-releases currently address quite diverse and multiple audiences, such as investors, business partners, employees, suppliers, bloggers, news media outlets, and customers as well as the general public. The main communicative objectives of e-releases involve large-scale announcing a company's activities, establishing, developing and maintaining contact with recipients, increasing the company's visibility, and shaping positive public opinion about it. The overarching goal of ereleases is the accumulation of publicity capital and the development of a positive corporate image (Ivantsiv, 2018). In theoretical terms, the e-release can be viewed as an adapted genre (Crowston \& Williams, 2000) which has moved to the Internet and has acquired some new functional characteristics.

The most influential research on traditional press releases has been conducted by Jacobs (1999a, 1999b, 2003, 2014), who was the first to identify metapragmatic characteristics of press releases such as self-reference, selfquotation and the use of explicit semi-performatives, as well as to reveal their important preformulating functions. Together with coauthors (Sleurs \& Jacobs, 2005; Sleurs, Jacobs, \& van Waes, 2003), he also studied the production of press releases in banking and telecommunications industries, and scrutinized the notion of preformulation by using an ethnographic approach.

A genre analysis of press releases was conducted by McLaren and Gurău (2005). Their research has shown that the move structure of press releases from the UK biotechnology sector can be schematically described as Announcement Elaboration - Comment (CEO) - Contact details - Editor's note, with the last move being optional. As these authors emphasize, factual reporting in the genre's texts interplays with striving "to present the company in as favorable a light as possible" (McLaren \& Gurău, 2005: 12). 
One study of the same type, based on a small corpus compiled from quite different sources, was done by Catenaccio (2008) who suggested a move structure of the genre, but without differentiating between its elements (such as the headline, boilerplate, or company's logo) and functional and semantic textual units. The main moves she revealed include Justifying the product or service, Detailing the product/service/company/other event which is the focus of the release, and Explicit promotional component (e.g. Emphasizing positive results). All of the above authors (Catenaccio, 2008; Jacobs, 1999a; McLaren \& Gurău, 2005) refer to the press release as a hybrid genre - the result of blurring the boundaries between discourses, as it seeks "both to inform and to persuade" (McLaren \& Gurău, 2005: 12).

Catenaccio (2007a) examined press releases issued by an Italian dairy company. The collected data were analyzed from a discourse perspective, and the salient features of the crisis communication strategy this company chose to use were revealed. In another study, Catenaccio (2007b) tried to clarify the role that press releases play in constructing corporate image and identities in the fashion industry. In this paper, press releases are viewed as "an eminently self-centred genre, and one especially suited to the expression and construction of identity" (Catenaccio, 2007b: 33).

In contrast, the genre status of the press release in biotechnology has been questioned by Lassen, who has suggested that it should not be considered a genre but rather a media-channel "used as a vehicle to carry a variety of rhetorical objectives" (Lassen, 2006: 506). However, this point of view is difficult to accept since the press release possesses, as other above mentioned researchers have shown, clearly identifiable and intertwined communicative purposes, allowing it to firmly establish a genre status.

More studies concentrated on other aspects of press releases or enhanced previous studies. Following Jacobs, Malekova (2013), for example, explored the phenomenon of self-reference as an instance of preformulation in the genre of institutional press releases within the framework of critical discourse analysis. Skorczynska (2016) conducted a comparative study of keywords in press releases from British, Spanish and Polish energy companies, while Ivantsiv (2018) approached the press releases of international cosmetics companies from a cognitive linguistic perspective and singled out two dominant metaphorical models of the image-making corporate discourse, which essentially contribute to shaping public opinion about these corporations.

Regarding specific characteristics of e-releases, research interest in them has so far been rather limited, involving only a brief overview of their novel linguistic features (see Catenaccio, 2007c; Jacobs, 2014; Skorczynska, 2020; Strobbe \& Jacobs, 2005). According to the available research, e-releases tend to combine the traditional preformulation features of paper press releases with a more direct type of discourse (Jacobs, 2014), which includes the use of superlatives, evaluative adjectives, imperatives, directly addressing the reader, and capitalized typography (Strobbe \& Jacobs, 2005). All these characteristics manifest the metamorphosis of 
e-releases into more promotional texts, which now serve as direct marketing tools (Catenaccio, 2007c; Skorczynska, 2020; Strobbe \& Jacobs, 2005).

As seen from the above overview, the studies of traditional press releases were based on texts from different business and social spheres and were conducted without attention to the influence which these spheres might have upon the linguistic characteristics of the texts. Only some of the e-releases' linguistic features have been addressed, mostly in the form of general observations, rather than as the results of specially conducted studies. Therefore, in the present paper we aim to enhance the existing research by exploring prominent genre characteristics of international cosmetics companies' e-releases. We assume that new functional possibilities (afforded by the electronic environment) will influence the features of e-releases in various ways. At the same time, we anticipate that the philosophy and ideology of the cosmetics industry, marked by striving to impose aesthetic values, may also leave some interesting impact on its e-releases. More specifically, we seek to find answers to the following research questions:

- What are the main structural, semantic, and linguistic features of the texts of international cosmetics companies' e-releases?

- How do these companies use the novel opportunities afforded by the electronic environment in the e-releases they issue?

- How do e-releases differ from their traditional counterparts?

\section{METHODOLOGICAL FRAMEWORK AND CORPUS}

The methodological approach to the study of e-releases adopted in this article follows the model of genre analysis suggested by Askehave and Nielsen (2005a, $2005 \mathrm{~b}$ ). This model takes into account the specific features of Internet genres created by the electronic medium. As Xia (2020: 145) indicates, it is most suited for the description of webpages and, consequently, for the analysis of e-releases, which appear as such pages.

The model suggests a two-stage procedure of analysis which reflects a bidimensional vision of Internet genres, as both media and texts. As Askehave and Nielsen (2005b) emphasize, recipients of Internet documents constantly experience modal shifts, acting either as traditional readers or navigators. It is, therefore, important to differentiate between the two modes, depending on a reader's position - the reading mode, which involves reading, skimming and scanning (Finnemann, 2017), and the navigation mode, which consists of navigation and browsing.

In accordance with this methodological approach, we conducted the analysis of e-releases of international cosmetics companies in two stages. In the first stage, the major focus was on e-releases as texts, or "printouts" of the webpages. The procedure of their analysis generally followed the one adopted in (Yakhontova, 
2002a, 2019). At the beginning of the first stage, the texts of e-releases were scrutinized for their overall organization with the aim of pinpointing the main structural elements. After the elements had been determined, we analyzed the most pragmatically important of them, namely headlines, boilerplates and the main bodies of the texts. Analysis of the headlines included consideration of their syntactic patterns, length, and prominent lexical features, which are important for implementing the communicative characteristics of cosmetics companies' ereleases.

Further, we proceeded with the study of the boilerplates and, consecutively, the main bodies of the texts. First, we were interested in the peculiarities of the semantic and functional organization of both groups of texts (boilerplates and main bodies) and used the same methodological procedure to analyze them. The procedure consisted in interpreting the content of the texts as a series of consecutive moves as used in Swales's (1990) genre analysis. Such moves are, in fact, stable functional units, which "reflect the conventionalized structuring of genre determined by its communicative purpose" (Yakhontova, 2002a: 219). It is worth emphasizing that although Swales himself recognizes that move analysis has been "over-explored in recent years" (Swales, 2019: 76), it still remains an effective instrument, which is widely used for identifying semantic and functional regularities in text organization.

Moves in the boilerplates and main bodies were examined through the process of text segmentation, which included detailed top-down reading of the texts for shifts in topics and relevant linguistic signals. A communicative function for each revealed fragment was identified with due regard to the global characteristics of e-releases. Then, the moves of both structural elements (the boilerplate and main body) were coded based on the names of their underlying functions. We separately conducted move analysis and then compared and discussed our findings to reach a consensus on the textual boundaries of moves and their labels.

Next, we concentrated on examining the most conspicuous linguistic elements within each move. The chosen research perspective for this part of the study was a stylistic one, implying that linguistic features are described not for their own sake but to show their functional significance in adequate interpretation of texts (Wales, 2001: 373). The considered features included (1) evaluative words, (2) stylistic devices (metaphors, similes, and repetitions), (3) personal pronouns, and (4) sporadically, the use of verb tenses. We tried to reveal the functional load of these elements and devices by examining the communicative purposes of the moves within the context of the adapted genre of the e-release.

In the second stage, e-releases were studied in the navigation mode, as webpages. We consecutively analyzed the role of those elements and features which were formed and added to paper press releases under the impact of an electronic environment. More precisely, we scrutinized the corpus of e-releases for the presence of (1) technological elements (headers, footers, and buttons), 
(2) links inside the textual parts and their types (internal or external), (3) images, 4) audio- and video files, and (5) the use of colors. Again, we were interested to see how these novel possibilities help to shape and objectify the genre characteristics of cosmetics companies' e-releases.

Throughout the investigation (in both stages) we tried to maintain a comparative perspective and discover, where possible, the "inter-company" differences in the structure, moves, and linguistic features of the textual part of ereleases, as well as any discrepancies in the use of technological opportunities.

The corpus of data used for this study consists of 60 press releases issued by three international US-based cosmetics companies, namely Avon Products Inc., Estée Lauder Companies Inc., and Mary Kay Inc. These corporations are among the world's leading manufacturers and marketers of quality skin care, makeup, fragrance, and hair care products. The e-releases were accessed on the companies' virtual newsrooms ${ }^{1}$ and chosen from those issued each year within the time period of 2015-2020. The number of e-releases produced by each company was 20, and the number of their e-releases issued in one year ranged from three to four. All ereleases in the corpus were labeled as EPR and consecutively numbered (EPR-1 to EPR-60).

The total length of the compiled corpus is 43,440 words, with the length of individual e-releases ranging from 210 to 1,740 words. The length of each subcorpora is as follows: Avon's e-releases - 14,934 words, Estée Lauder's - 15,182, and those of Mary Kay - 13,324. The topics covered by e-releases in the corpus include information on business updates (8 texts), appointments and staff changes in upper levels of management (5), business developments, such as the opening of a new facility or expansion into a new market (3), partnerships or collaborations with other companies, institutions or public figures (10), various public initiatives (18), new cosmetics products released by companies (9), and awards (7) received by a company, its employees, or products. We intentionally decided to work with a corpus of a wide thematic repertoire to obtain a more general picture of the international cosmetics companies' e-releases.

\section{RESULTS}

\subsection{E-releases as texts}

E-releases of three international cosmetics companies, considered in the reading mode, display an identical structure consisting of such main elements as the headline, main body, and boilerplate. Other components relevant to the identification of the genre - the date, contacts, and episodic forward-looking

\footnotetext{
${ }^{1}$ https://about.avon.com/us-about/news, https://www.elcompanies.com/en/news-andmedia/newsroom, https://newsroom.marykay.com/
} 
statements (that is, the statements which project future business events or results) - are "marginal in terms of their contribution to press release content" (Catenaccio, 2007a: 160) and will not be considered in this paper. We will begin with the analysis of structural elements other than the main body.

\subsubsection{Headlines}

The first element of e-releases is the headline which, in news media texts, traditionally aims at summarizing the content and attracting the attention of readers. In our corpus, the headlines exhibit three structural patterns identified and labeled as in Yakhontova (2002b). As seen from Table 1, one-sentence constructions in the form of a declarative sentence with the verb in the present tense are the most common. Such headlines condense the content of e-releases and present it in an easily comprehensible form, thus allowing the readers to immediately grasp the reported information.

\begin{tabular}{|l|c|c|l|}
\hline \multirow{2}{*}{\begin{tabular}{c}
\multirow{2}{*}{$\begin{array}{c}\text { STRUCTURAL TYPES OF } \\
\text { HEADLINES }\end{array}$} \\
\cline { 2 - 3 } One-sentence construction
\end{tabular}} & \multicolumn{2}{|c|}{$\begin{array}{c}\text { QUANTITY } \\
\text { (OUT OF 60/100) }\end{array}$} & \multicolumn{1}{c|}{ EXAMPLE } \\
\hline NUMBER & PERCENTAGE & \\
\hline Verbal constructions & 10 & 75 & $\begin{array}{l}\text { Sofia Vergara and Avon Announce New } \\
\text { Fragrance (EPR-3) }\end{array}$ \\
\hline $\begin{array}{l}\text { "Colon" and other two-part } \\
\text { constructions }\end{array}$ & 5 & 17 & $\begin{array}{l}\text { Actress and Singer Debby Ryan Named } \\
\text { New Voice For Mary Kay Dating Abuse } \\
\text { Prevention Campaign (EPR-38) }\end{array}$ \\
\hline
\end{tabular}

Table 1. Structural types of headlines and their quantitative distribution in the texts of e-releases

The other two types of headlines are also clearly informative or, in Ifantidou's (2009) terms, semantically determined, and require a minimal investment of receptive efforts (Dor, 2003) on the part of the readers. All of the headlines contain keywords from the main bodies of the texts and explicitly mention the name of the company (see examples in Table 1) which issued the e-release, thus acknowledging this advice provided in one of the press release writing manuals: "If you're trying to build a brand or fill the search engines with positive news about your company, your company name might be the main keyword" (Thaeler, 2009: 56). Furthermore, all of the headlines reveal "an urge to express actions" (Schneider, 2000: 57) as they are based on verbs or verbal forms. The effect of dynamism, created by the use of verbs, helps to position the companies issuing the e-releases as commercially energetic and proactive.

At the same time, we observed some "inter-company" linguistic differences: while the headlines of Avon and Estée Lauder corporations are stylistically neutral, 
those of Mary Kay include promotional self-definitions, such as an "iconic beauty company" or "global cosmetic powerhouse". Overall, the structural patterns of headlines and their clearly informative character provide the possibility for their functioning as stand-alone news texts. As such, they attract the attention of their readers by providing a sufficiently exhaustive preview of the content rather than by using any special rhetorical or lexical devices. These features help to effectively contribute to one of the important communicative purposes of e-releases - largescale announcing the company's activities.

\subsubsection{Boilerplates}

While the headline is a starting point of the e-release, at the end is the boilerplate "the standard, company-approved summary that explains some basics about the company" (Aronson, Spetner, \& Ames, 2007: 74), usually labeled as About and followed by the company's name. In the e-releases we analyzed, most have several boilerplates, which provide information related to a particular topic; for example, in texts focusing on new business partnerships, there is usually a boilerplate about a partner company. We will further focus only on the boilerplates providing information about the companies in question (Avon, Estée Lauder, and Mary Kay). These appear in all texts of the compiled corpus and thus can be treated as obligatory structural elements.

Boilerplates are clearly separated from the main bodies of e-releases and appear as stand-alone, relatively short texts (with the length in the corpus varying from 60 to 130 words), as in the following example:

\footnotetext{
"Irresistible products. Positive community impact. Rewarding opportunity. For more than 50 years, Mary Kay has offered it all. With 3.5 million Mary Kay Independent Beauty Consultants and $\$ 4$ billion in global annual sales, Mary Kay is a top beauty brand and direct seller in more than 35 markets around the world. Discover what there is to love about Mary Kay by connecting with a Mary Kay Independent Beauty Consultant at marykay.com" (EPR-41).
}

Furthermore, the boilerplates of each company are similar in their structure and wording, periodically showing only slight variations. These variations may be related to the theme of an e-release or are caused, most often, by deliberate changes (after a certain time period), made by a company in order to refresh the boilerplate information and, consequently, the impression it makes. The boilerplates are thus short and mostly reusable texts which possess a number of easily identifiable moves (and, in some cases, steps) shown, with examples, in Table 2. 


\begin{tabular}{|c|c|c|}
\hline MOVES AND STEPS & NUMBER (OUT OF 60) & EXAMPLES \\
\hline 1. Introducing the company & 60 & $\begin{array}{l}\text { The Estée Lauder Companies Inc. is } \\
\text { one of the world's leading } \\
\text { manufacturers and marketers of } \\
\text { quality skin care, makeup, fragrance } \\
\text { and hair care products (EPR-21) }\end{array}$ \\
\hline $\begin{array}{l}\text { 2. Sharing the company's achievements } \\
\text { a) by emphasizing financial results or } \\
\text { those related to its global influence } \\
\text { and/or } \\
\text { b) by advertizing its products }\end{array}$ & 60 & $\begin{array}{l}\text { As a multibillion-dollar company we } \\
\text { offer the latest in cutting-edge skin } \\
\text { care, bold color cosmetics and } \\
\text { fragrances (EPR-60) }\end{array}$ \\
\hline $\begin{array}{l}\text { 3. Presenting the company's social or } \\
\text { philanthropic activities }\end{array}$ & $\begin{array}{c}40 \\
\text { (in Avon and Mary } \\
\text { Kay's e-releases) }\end{array}$ & $\begin{array}{l}\text { Avon has a } 130 \text { year history of } \\
\text { empowering women through } \\
\text { economic opportunity, and the } \\
\text { company also proudly supports } \\
\text { the Avon Foundation for Women } \\
\text { in its efforts to end breast cancer } \\
\text { and domestic violence (EPR-4). }\end{array}$ \\
\hline $\begin{array}{l}\text { 4. Extending an invitation to visit the } \\
\text { company's website }\end{array}$ & $\begin{array}{c}40 \\
\text { (in Avon and Mary } \\
\text { Kay's e-releases) }\end{array}$ & $\begin{array}{l}\text { Discover what there is to love about } \\
\text { Mary Kay by connecting with a Mary } \\
\text { Kay Independent Beauty Consultant } \\
\text { at marykay.com (EPR-35) }\end{array}$ \\
\hline
\end{tabular}

Table 2. Moves and their quantitative distribution in the boilerplates of e-releases

As seen from Table 2, the first two moves occur throughout the corpus and can be treated as obligatory ones. However, there is variation in the presence of the last two moves, which correlates with some features of their linguistic manifestation. While the boilerplates of Estée Lauder's e-releases consist of two moves and contain self-promotional elements in the first one only, those of the other two companies contain additional moves and use abundant evaluative devices to explicitly characterize their status, role, and activities (see the underlined words and phrases). Furthermore, as in the case with headlines, Mary Kay's boilerplates are more straightforward and, at the same time, more sophisticated in their advertizing of the company: for instance, Mary Kay metaphorically calls itself (in several boilerplates) "one of the original glass ceiling breakers" or "top beauty brand", and defines its products as "irresistible".

Such linguistic features, particularly prominent in Mary Kay and, partially, in Avon's e-releases, enhance, in our opinion, the communicative purpose of a boilerplate which Catenaccio (2008: 24) defined as "establishing credentials". Our data show that boilerplates not only distribute information "that may or may not be used by journalists and/or needed by other stakeholders" (Catenaccio, 2007a: 160), but, first and foremost, promote their companies and contribute to the formation of their positive corporate images. This function of e-releases is most prominently found in the main bodies of their texts. 


\subsubsection{Main bodies of e-releases}

The analysis conducted has allowed us to identify five moves in the main bodies of e-releases three of which, as Table 3 shows, occur in 50 to 60 texts, that is, in the majority of the corpus. We will begin with the consideration of these three major moves (their numbers and names are provided in boldface for better visibility).

\begin{tabular}{|c|c|c|c|}
\hline No & MOVES & $\begin{array}{l}\text { NuMbER OF TEXTS } \\
\text { (OUT OF 60) }\end{array}$ & EXAMPLES \\
\hline 1a. & Describing a social problem & 4 & $\begin{array}{l}\text { With warm weather fast approaching, the prime season } \\
\text { for mosquito-borne illnesses like the Zika virus is back. } \\
\text { This spring, proper protection is even more important } \\
\text { as the threat of mosquito-borne illness continues to be } \\
\text { on the rise (EPR-10). }\end{array}$ \\
\hline 1. & Introducing the company's news & 60 & $\begin{array}{l}\text { The Estée Lauder Companies Inc. announced today that } \\
\text { it has invested in DECIEM, a fast-growing, vertically } \\
\text { integrated multi-brand company, driven by a } \\
\text { consumer-centric focus that is already impacting the } \\
\text { world of beauty. Terms of the investment were not } \\
\text { disclosed (EPR-30). }\end{array}$ \\
\hline 2. & Providing details about the news & 56 & $\begin{array}{l}\text { Created in partnership with the prestigious fragrance } \\
\text { house of Firmenich, Prima is an ethereal, floral-chypre } \\
\text { fragrance - delicate, feminine and quietly powerful. } \\
\text { The scent is a collaboration by two Firmenich } \\
\text { perfumers, Frank Voelkl and Master Perfumer Harry } \\
\text { Fremont. Prima opens with lush top notes of plum, } \\
\text { balancing its sweetness with a hint of tangy bergamot. } \\
\text { Next, it unfolds to reveal a rich heart of intoxicating } \\
\text { rose, a stunning blossom with ruffled pink petals that } \\
\text { echo the folds of a dancer's skirt. Finally, there's a jeté } \\
\text { to rich clearwood: reminiscent of the satiny barres in a } \\
\text { ballet studio, the woodsy note comes alive on skin, } \\
\text { melding with oak moss and patchouli for a warm, } \\
\text { poetically graceful finish (EPR-4). }\end{array}$ \\
\hline 3. & Commenting on the news & 50 & $\begin{array}{l}\text { "I am proud of our accomplishments. Importantly, we } \\
\text { are well-positioned for continuing growth through our } \\
\text { unique creativity and consumer appeal for our brands } \\
\text { and innovative products. Global prestige beauty is a } \\
\text { dynamic industry, and we will continue to anticipate } \\
\text { and target the areas with the greatest potential..." } \\
\text { (EPR-55). }\end{array}$ \\
\hline 3a. & $\begin{array}{l}\text { Providing relevant information } \\
\text { about a company }\end{array}$ & 13 & $\begin{array}{l}\text { Every year, Mary Kay conducts hundreds of thousands } \\
\text { of scientific tests on products and ingredients to ensure } \\
\text { the highest standards of safety, quality and } \\
\text { performance. Mary Kay holds more than } 1,500 \text { patents } \\
\text { for products, technologies and packaging designs in its } \\
\text { global portfolio. Recently, the company announced the } \\
\text { opening of a more than } \$ 100 \text { million state-of-the-art } \\
\text { manufacturing and R\&D facility in Lewisville, Texas } \\
\text { (EPR-16). }\end{array}$ \\
\hline
\end{tabular}

Table 3. Moves and their quantitative distribution in texts of e-releases 
The Introducing the company's news move is the initial move in all texts of the corpus. It occupies the first, strategically important paragraph (called "a lead" in journalism studies). The main function of this move is to announce and summarize a piece of news which is the focus of the e-release, as can be seen from the example in Table 3. Such a beginning obviously corresponds to a historically elaborated news style, "prefabricated" (Bell, 1991: 58) and replicated in numerous news media texts.

The linguistic characteristics of the move, rather conspicuous in their heterogeneity throughout the corpus, entirely coincide with such preformulation features, identified earlier by Jacobs (1999a, 1999b, 2003, 2014), as the thirdperson self-reference with the name of a company in the subject position, the use of the historically inherent simple past, and the frequent occurrence of the word "today", which warrants the newsworthiness of a press release. However, what marks this move in the cosmetics companies' e-releases is its extremely selfpromotional and self-evaluative style. Its obvious presence in the texts somewhat contradicts previous observations and conclusions on the deliberate neutrality of press releases (Jacobs, 1999b: 232) or on the concentration of evaluative words found mainly in quotations (Catenaccio, 2007a: 160). Quite the opposite, the first move of cosmetics companies' e-releases is abundant in lexemes of positive evaluation and/or phrases which possess highly positive connotations in today's news media and society (see the underlined parts of the examples in Table 3). Furthermore, traditional self-references are reinforced (in one-third of the corpus) by a short and highly promotional self-description of the company immediately after the first mention of its name, e.g. "the global leader in prestige beauty" (Estée Lauder), "the leading social selling company" (Avon), or "top beauty brand" (Mary Kay). All these elements (i.e. self-references and highly promotional selfdescriptions) help to enhance a company's image and to promote the activities/awards/persons/products, etc. it reports about in its e-releases.

The concentration of promotional elements becomes higher in the second Providing details about the news move, which occurs in 56 texts (see Table 3). It should be noted that the absence of this move in a small number of texts is a deviation, which is quite common for texts of any genre (Yakhontova, 2002a: 219). This second move generally follows the first one (in 38 out of 56 texts), but also occurs in a cyclic manner, after the first one and then again after the third move.

The communicative function of the move consists of sharing relevant information or details about the news the e-release focuses on. A careful linguistic analysis of these functional parts has shown that they build upon the combination of description and evaluation as generic values complementing each other and are characteristic of advertizing discourse and genres (Bhatia, 2005). This combination of values allows for the differentiating of a piece of news as if it were a product.

The number of explicit promotional linguistic devices is quite noticeable in the e-releases that report about awards and social activities, as in the following part of the second move: 


\begin{abstract}
"The evening will feature an on-stage discussion between Mr. Lauder and Tom Ford - fashion designer, film director and Chairman of the Board of the Council of Fashion Designers of America. The conversation will explore Mr. Lauder's illustrious career, his role as a champion of women in the beauty industry and beyond, and the intersection of art, fashion, beauty, and culture. This will be followed with a tribute performance by Academy Award-winning actress and singer Jennifer Hudson on the magnificent Adrienne Arsht Stage. Modern elegance is the inspiration behind the evening, which will begin with a welcome champagne reception and conclude with a seated dinner in Alice Tully Hall" (EPR-21).
\end{abstract}

The description of the event in this example is combined with its immediate evaluation of the targeted central figure (Mr. Lauder) himself as well as of other participants and the location of the event. The use of evaluative lexis with emotive shades of meaning (illustrious, magnificent, elegance, inspiration) and the references to art, fashion and beauty produce not only a generally positive but also an aesthetic impression.

At the same time, textual passages, utilizing the second move in e-releases' presentation of new products, are even more rhetorically and linguistically elaborate. This especially concerns the descriptions of products, which functionally resemble boilerplates. Their discourse is, in fact, close to that of advertizing, and as such, it displays some of the distinctive features which have already been postulated for advertisements, namely, the foregrounding of connotational and metaphorical meanings, parallelism between various semiotic modes, the combination of the voices of authority and intimacy, the use of allusions, and the induction of moral and/or aesthetic judgments (Cook, 2001: 220). The passage exemplifying move 2 in Table 3, which impressively presents a new perfume, features many prominent characteristics of advertisements: the metaphorical transfer of notions, in this case, from the domain of ballet (pink petals that echo the folds of a dancer's skirt, jeté to rich clearwood, satiny barres in a ballet studio); the induction of poetic visual images through the lexemes related to forest flora (clearwood, woodsy, oak moss) used together with evaluative words; appeals to the senses and visual perception through words denoting fruit and flowers used in elegant phrases (lush top notes of plum, tangy bergamot, rich heart of intoxicating rose, etc.). Such descriptions target the emotional sphere of e-releases' recipients, invoke aesthetic feelings, and contribute to the formation of the company's image as a producer of exquisite cosmetics.

The highly evaluative tone of e-releases' discourse is further maintained in the third, Commenting on the news move (found, as Table 3 shows, in 50 texts). It generally follows but may also precede the second move, occupies one or two paragraphs, and is written using quotations. As researchers of press releases indicate, they are pseudoquotes, because they are invented, attributed to important figures in the company's management or other relevant persons (e.g. partners), and then presented as real ones (Catenaccio, 2007a; Sleurs \& Jacobs, 2005; Sleurs et al., 2003). The main function of these fictional quotations is to 
additionally promote a reported event, activity, or product, making, at the same time, the discourse of press releases more lively and, simultaneously, factual, distanced and objective (Erjavec, 2004; Sleurs et al., 2003). This emphasized objectivity, achieved through the inclusion of the exact words of other persons, is, in fact, an effective means of persuasion.

As can be seen from the example of this move in Table 3, the quotation used in the third move is full of lexemes which very positively evaluate the activity of the company. Another typical rhetorical feature of this move is a promise for the future which the speaker gives, again using evaluations (we will continue... to target the areas with the greatest potential), thus additionally reinforcing an aggressively promotional tone of speech.

Also, the move is linguistically manifested through various types of repetition, often used in this move for the purpose of emphasis, e.g.:

"We are very proud to enter this critical category with a highly innovative, high performing line of products" (EPR-14).

Another form of repetition detected in the texts is a stylistic device of chiasmus based on the use of the same elements in reverse order:

"Ms. Goldman commented, “The right product has the power to change a woman's life, and each woman has the power to change the world" (EPR-19).

Such parallel repetition, traditionally used "for witty or aphoristic effect" (Wales, 2001: 54), essentially enlivens the discourse of e-releases.

In addition, the third move exhibits the phenomenon of over-lexicalization, which consists in the use of synonymous or near-synonymous evaluative words "which contribute to the co-referentiality of the success of an organization, its products or services" (Erjavec, 2004: 565), e.g.:

"Our goal is to make the direct-selling model and the Representative experience more contemporary, efficient, and profitable by reinvigorating the Avon brand..." (EPR-1).

Overall, lexical redundancy in the third move of e-releases makes the information they contain recognizable, increases its importance, enhances impact on the target audience, and promotes a positive image of a company.

The third move is also marked by the wide use of metaphors and metaphorical models, which contribute to the formation of a cosmetics company's striking corporate image. The following examples from pseudoquotes metaphorically conceptualize the company as a warrior fighting for the beauty of its customers and as a protector of their well-being: 
"Avon, with their army of passionate and committed Representatives, is showing how the power of partnership can make a positive difference" (EPR-17).

“Since we can't avoid these aggressors completely, our newest skin care line introduces the latest in skin science to provide powerful antioxidant protection with visible results to help defy the look of aging" (EPR-47).

Such metaphorical models, also present in other moves (see Ivantsiv, 2018), contribute to the development of the cosmetics company's powerful and vivid corporate image, which is portrayed, through the words of its top management and partners, as a perfect organism, able to create masterpieces, face societal challenges, and meet the needs and expectations of its clients.

One more conspicuous feature of the third move is connected with the perspective, or point of view, chosen in the quotations by their alleged authors. As Ensink and Sauer (2003: 10) indicate, the normal perspective is that of a speaker. Most often, it is manifested through the use of the first-person pronoun $I$ and appropriate possessive pronouns. However, our study shows (see Table 4) that $I$, $m e, m y$, and you are much less quantitatively prominent in quotations than we and related possessives. The dominance of this exclusive we and the appropriate possessive forms obviously signals that quoted persons speak on behalf of their companies and adopt corporate identities (see the example in Table 3). At the same time, the use of $I$ personalizes quotations, increases the trustworthy character of the information they contain, and helps to evoke confidence in their recipients, thus counterbalancing the effect of neutrality produced by a thirdperson reference in the first move.

\begin{tabular}{|c|c|c|c|c|c|c|}
\hline \multicolumn{2}{|c|}{ DISTRIBUTION OF PERSONAL PRONOUNS } & \multicolumn{4}{c|}{ DISTRIBUTION OF POSSESSIVE PRONOUNS } \\
\hline We $/$ us & $I / m e$ & You & Our & Ourselves & My & Myself \\
\hline $170+27$ & $66+16$ & 12 & 179 & 1 & 16 & 0 \\
\hline
\end{tabular}

Table 4. Distribution of personal and possessive pronouns in the third move of e-releases

Our study has also shown that e-releases may contain two more moves. The first of them, marked as 1a in Table 3 (Describing a social problem), appears only in those texts which announce social or philanthropic activities of a company. The communicative function of this move is to introduce the social problem to which the company responds (e.g. Zika virus in the example in Table 3). Unlike the first additional move, the second additional move $(3 \mathrm{~b}$ in Table 3 , Providing relevant information about a company) has been found at the end of the main bodies, in this case, in 13 of the e-releases. Its functional organization resembles that of a boilerplate, adjusted to the topic of the e-release. For instance, the example in Table 3 presents the achievements of Mary Kay thematically related to the announced news, namely, the conducted research on the impact of antioxidants on 
skin health. The purpose of this move seems to be obvious: it aims to additionally promote the company, its products, services, and activities.

\subsection{E-releases as webpages}

Further, we analyzed e-releases in the navigation mode, as website pages. As our study has revealed, the three cosmetics companies use rather different approaches in presenting e-releases in the newsrooms of their corporate websites. These approaches and ways, used by each company, will separately be considered due to their variability.

\subsubsection{Avon's e-releases}

Avon provides a list of chronologically arranged e-releases with headlines as links which direct to the webpage where a particular e-release is placed. Surprisingly enough, these webpages do not display any interesting technological features, having only a header with the buttons, which allows one to navigate the corporate website, and a footer with links to relevant judicial information and the company's pages in social media (provided, however, in extremely small font and symbols). The e-releases located there insignificantly differ from their printouts: out of 20, 5 look like usual texts, while 15 possess a limited number of links in the form of pink colored words (the color associated with the company) within the texts (see Fig. 1).

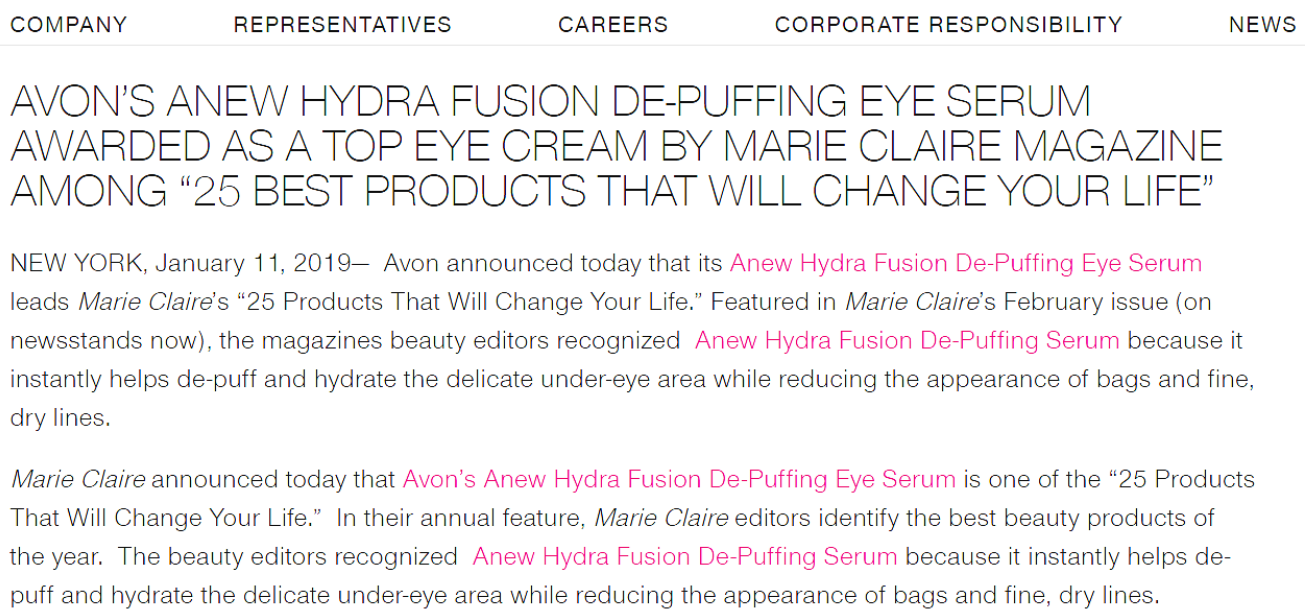

Figure 1. Snapshot of Avon's e-release fragment

All of these links are internal, that is, they lead to documents located on the same server (Bolaños Medina et al., 2005: 138). They re-direct the readers of ereleases to those webpages which advertize or sell the company's products. The purpose of such links is obvious: they help consumers to quickly find what they are 
most interested in, and thus help to promote their products and the company itself. Avon's e-releases do not contain any images, videos or graphics, the only exception being one text with a photo of a newly appointed staff member. Furthermore, the faded fonts of the texts (see Fig. 1) produce the impression of somewhat "old" texts. However, this is not surprising, because e-releases on the companies' websites reproduce source versions, distributed, for example, by such a service as Businesswire, and are kept primarily for storing purposes.

\title{
3.2.2. Estée Lauder's e-releases
}

A more or less similar approach to displaying e-releases is exhibited by Estée Lauder. Its e-releases are also chronologically organized but can be filtered according to thematic criterion. Their presentation on the list appears to be more lively and colorful because each headline is accompanied either by a photo or other type of image, relevant to the e-release's topic, or by their logo - a dark blue rectangle with the company' name in the middle. However, the webpages where the texts of e-releases are located look very similar to those of Avon and, furthermore, contain even fewer links (see Fig. 2).

\section{ESTEEE LAUDER COMPANIES}

\section{ELC Named to Working Mother's 2019100 Best Companies List}

\begin{abstract}
PRESS RELEASE, OCT 3, 2019
NEW YORK, NY (September 24, 2019) - Working Mother revealed its annual list of the 2019100 Best Companies today, representing more than 2 million employees in the U.S. This year's winners are focusing on inclusive benefits for families, including gender-neutral parental leave, gradual phase-back after leave, and accessible, affordable childcare. The Estée Lauder Companies (ELC) was among the 100 companies that earned a spot on this year's list.

"Our 100 Best Companies are the standard of excellence and continue to pave the way with the work they are doing on behalf of working parents and caregivers in the U.S.," says Subha Barry, president of Working Mother Media. "We celebrate their efforts and applaud them for addressing the needs of this important and ever-growing sector of talent."

"We are honored to be named to Working Mother's annual list of 100 Best Companies this year. This recognition highlights The Estée Lauder Companies' leadership in family-related benefits and commitment to cultivate a best-in-class work environment for all employees. We are especially proud to be recognized for our enhanced and inclusive family-related programs, policies and benefits for our U.S. employee base," said Marilu Marshall, Senior Vice President, Chief Inclusion and Diversity Officer, The Estée Lauder Companies.
\end{abstract}

Figure 2. Snapshot of Estée Lauder's e-release fragment

These links use blue colored words (in agreement with the color of the company's logo) and are found in 50 per cent of Estée Lauder's e-releases. Their average number per text, however, is only 2 . The links are either internal, directing readers to the company's website, or external, which lead them to other websites (Bolaños Medina et al., 2005: 138), for example, to those of partner organizations. 
Four texts contain photos of people which the e-releases focus on. Overall, Avon and Estée Lauder's e-releases almost coincide with their textual printouts, using only a limited number of navigation opportunities. This observation confirms Sleurs and Jacobs's (2005: 1252) opinion on corporate websites as parading largescale online press releases' archives, which can be asynchronously read.

\subsubsection{Mary Kay's e-releases}

However, Mary Kay's e-release pages demonstrate a somewhat different approach to their presentation. As in the case with Estée Lauder's website, they are located on the appropriate newsroom's webpage, arranged in chronological order and accompanied by photos. Each e-release, when accessed by clicking on its headline or the 'Read more' button, looks like a full-fledged webpage, in contrast to those of Avon and Estée Lauder's. Each of Mary Kay's e-release pages has two headers which allow for navigation of the newsroom and the corporate site itself. The press release text is located following a large and downloadable photo which may illustrate the described news, present the company's logo or add decoration, as Fig. 3 shows.

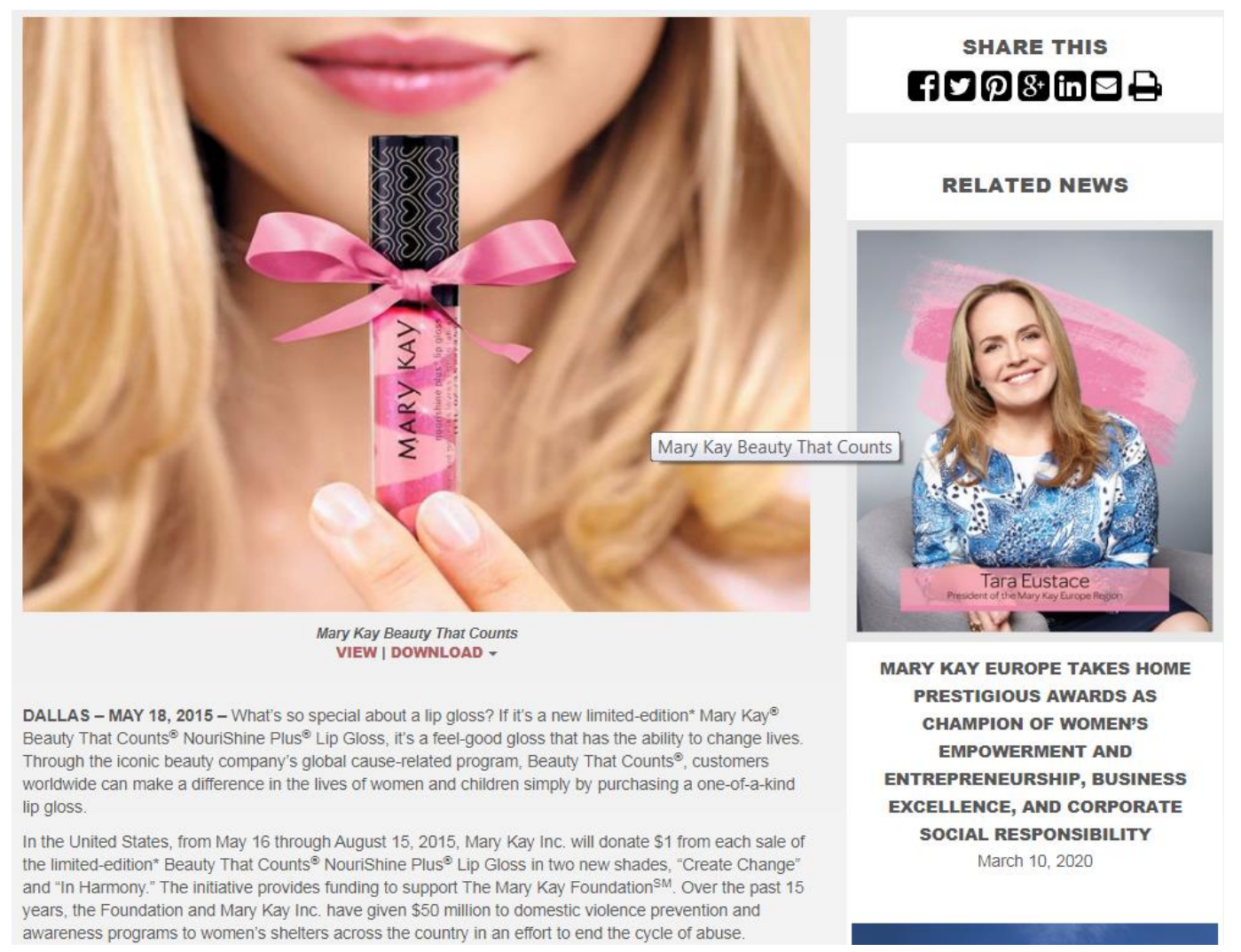

Figure 3. Snapshot of Mary Kay's e-release fragment 
The e-releases of Mary Kay are organized along vertical and horizontal axes. As seen from the provided fragment, the press releases' texts are located on the left side of the page. They have only one or two links inside which, as in the case with Avon and Estée Lauder's texts, are in pink - the color of Mary Kay's brand (this color is also present in other structural parts of this company's e-releases). These links are either internal or external. The right-side part of the e-releases presents additional content categories, which include 'Related news' (with photos and headlines), 'Share this' and 'Follow Mary Kay' rubrics with iconic buttons, and 'Media contact' and 'Useful links'. These categories provide navigation options which create a wider platform for the reception of the main textual parts of the ereleases and help to enhance the image of the company and its activities. Such an organization of the e-release webpage was observed by Kress and van Leeuwen (1996), who emphasized that the information located on the left (in this case, the text of a press release itself) is usually perceived as something "given," while that on the right usually signals something new.

Both left and right parts are horizontally placed above a noticeable structural element found in all e-releases. It consists of the product promise, that is, the declared commitment made to customers, and another boilerplate, which may differ or be similar to that in the text of a press release (see Fig. 4). According to Kress and van Leeuwen (1996), such spatial location presents information as more practical and "real".

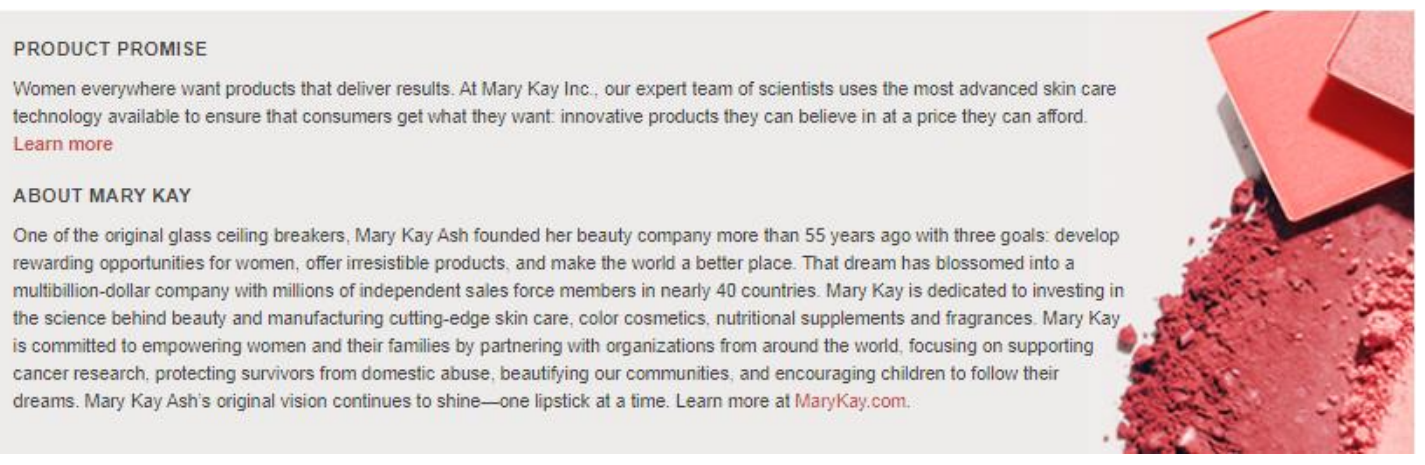

Figure 4. Snapshot of Mary Kay's e-release product promise and additional boilerplate

Thus, Mary Kay's e-releases consist of a static main textual part (reinforced by an additional boilerplate component) and a more dynamic part which portrays the company as active and open to communication, thus promoting its attractive image. Overall, these e-releases produce a bright, colorful impression due to the presence of photographs and the persistent use of pink color in their different elements, which makes "distinct elements cohere" (Machin \& van Leeuwen, 2007: 109).

It should be noted that none of the companies use audio- or video files in their e-releases, although four of them contain links, directing readers to archived webcasts and podcasts. 


\section{DISCUSSION}

In this article, we focused on the genre features of international cosmetics companies' e-releases. We performed a two-stage analysis of their overall structure, moves, prominent linguistic features, and new digital possibilities.

First, we attempted to find the main structural elements which the textual parts of e-releases possess. As our study shows, they preserve the overall organization which is typical of paper press releases, its main components being headlines, main bodies, and boilerplates. The first structural elements of e-releases - the headlines - primarily perform an informative function and build upon three syntactic patterns. However, the final element of e-releases - the boilerplate seems to be primarily promotional as the moves it possesses are solely aimed at advertizing the company rather than simply giving information about it.

Further, we found that three functional moves, constituting the e-releases' main bodies, are generally similar to those analyzed by other researchers based on texts from different social spheres. For example, the move labeled in this paper as Introducing the company's news functionally and semantically corresponds to the Announcing newsworthy information and Announcement moves, identified by McLaren and Gurău (2005) and Catenaccio (2008), respectively, while Providing the details about the news and Commenting on the news moves match Elaboration and Comments in McLaren and Gurău's research as well as three moves Uustifying the product or service, Detailing the product or service, and Explicit promotional component), analyzed by Catenaccio (2008). At the same time, the studied ereleases exhibit the presence of two other moves - Describing a social problem and Providing relevant information about a company. Consequently, a question arises as to the factors which have triggered the emergence of these moves: are they specific to the e-releases of international cosmetics' companies or to the adapted genre of the e-release?

It seems that the answer to this question would inevitably combine both alternatives. The presence of the Describing a social problem move suggests that it is primarily determined by the intention of cosmetics companies to publicize themselves as socially responsible businesses, whereas the Providing relevant information about a company move appears to support and sustain the broad promotional purposes of advancing brands, products, and services online, characteristic of e-releases. At the same time, the occurrence of the Describing a social problem move may also be the result of efforts to promote a company, albeit in a different way.

The same interplay of industry-specific and technological factors seems to shape the linguistic features of e-releases. As our study has shown, the e-releases of cosmetics companies are marked by explicitly self-evaluative, highly promotional, emotional, and even, sporadically, poetic discourse. The presence of these features can be attributed, on the one hand, to aesthetic concepts, which cosmetics companies widely use in the marketing of beauty care products. At the 
same time, it is generally known that the Internet as an "immensely empowering, individualistic, creative medium" (Crystal, 2001: 239) liberalizes verbal communication and potentially increases the richness of language. Therefore, abundant use of linguistic devices such as evaluations, metaphors, or various types of stylistically marked repetitions may also be attributed to the impact of the electronic channel.

As to digital functionality, it is used by cosmetics companies differently. Avon and Estée Lauder seem to rely, first and foremost, on the online distribution services and merely archive their e-releases on their corporate websites. Mary Kay, with its e-releases looking like multimodal ensembles (Jewitt, 2013), seems to pursue various marketing strategies which use, both through distributors and its corporate website, every opportunity to promote its image and create a favorable reputation.

Finally, we will try to provide a possible answer to the question about the differences between paper press releases and their electronic counterparts. As it was mentioned at the beginning of the paper, traditional press releases were intended to provide media coverage, which "includes responding to inquiries and building relationships with journalists" (Thaeler, 2009: 5). Such relationships required proving the credibility of the companies, because journalists tended to distrust overtly subjective and self-promotional texts (Jacobs, 1999b). Therefore, the writers of press releases, as Jacobs (1999b: 232) argues, tried to make their texts look neutral through the use of some preformulation devices, such as the third-person reference.

This situation seems to have radically changed with the emergence of the Internet and consequent possibilities to address diverse and potentially unlimited audiences. The issuers of e-releases do not need third parties like journalists any more and are able to directly promote their products and services to everyone everywhere by using a wide spectrum of new technological opportunities on the Web. These new circumstances have influenced, as our study shows, the characteristics of international cosmetics companies' e-releases at all levels of their organization. First, their language has become explicitly self-evaluative and at the same time richer and more interesting. Second, they seem to have developed a new move and transformed the boilerplate from a source of information into a direct marketing instrument. Third, e-releases possess new functional opportunities which may be used in accordance with companies' individual preferences. Furthermore, these new features seem to enhance the communicative purposes of this adapted genre by shaping its communicative intention to influence the recipients' emotional state and behavior. All these conspicuous characteristics bring e-releases into a class of commercial communicative phenomena, which Erjavec (2004: 554) called "promotional news" and Desnica (2018) - "consumption news briefs". A criterial feature of this type of news is the positive presentation of a company and its activities or products and the avoidance of any negative or controversial issues. 
However, we have to admit that e-releases continue to preserve such traditional characteristics and elements like overall structure, informative and rhetorically neutral headlines, preformulation features inherent in traditional press releases, and a general template of three major moves. Their presence ensures the recognizability of e-releases as novel modifications of existing ones and their appropriate identification by recipients. Such combinations of "old" and new features support the vision of genres on the Internet as inscribed into the hypertext-based electronic environment with some added features (Finnemann, 2017).

At the same time we can consider e-releases from a somewhat different theoretical perspective, especially given the claim that "the press release, as a way to reach the news media, is essentially dead" (Thaeler, 2009: 5). It is possible to assume that the traditional press release has undergone the process of genre reincarnation, which we define as the revival of genres on a novel (technological) basis. The e-release can thus be treated as a reincarnated genre, which substituted its predecessor due to a new digital reality and has developed new features, simultaneously preserving its conventional ones.

We also need to emphasize that the present study of e-releases is an exploratory one. Therefore, further research on e-releases from other business and social spheres is needed to provide more insights into their various and, probably, evolving characteristics.

\section{PEDAGOGICAL APPLICATIONS}

Since the e-release is a central public relations genre, it is not surprising that the ways of its effective production are often addressed in English for Specific Purposes (ESP) university programs and courses and have become the focus of many published materials (see, for example, Aronson et al., 2007; Thaeler, 2009), and even more Internet articles. It should be noted, however, that such materials are usually limited to general recommendations about the presence of key elements and the necessity to write in a clear and stylistically consistent manner. Therefore, the results of the reported analysis, which sheds light on the structural patterns, linguistic features and new functional possibilities provided by the digital channel as well as on their cumulative role in achieving communicative purposes of cosmetics companies' e-releases, can help to enhance and enrich ESP courses and teaching materials. For example, the findings can be used to provide useful move templates for writing boilerplates and main bodies of e-releases. The rich stylistic material collected in this study can potentially be utilized in the tasks aimed at developing creativity in using the appropriate vocabulary in public relations writing. Also, observations on the variability of technological features of e-releases, driven by different pragmatic factors, can inform students of the potentially broad range of digital possibilities and the situations when they may or 
may not be applied. From a broader perspective, the results of the study can be used to highlight the relationships between communicative purposes of e-releases, their audiences, and particular linguistic and technological choices.

[Paper submitted 10 Aug 2020]

[Revised version received 14 Dec 2020]

[Revised version accepted for publication 12 Jan 2021]

\section{References}

Aronson, M., Spetner, D., \& Ames, C. (2007). The public relations writer's handbook: The digital age (2nd ed.). Jossey-Bass.

Askehave, I., \& Nielsen, A. E. (2005a). What are the characteristics of digital genres?: Genre theory from a multi-modal perspective. Proceedings of the 38th Hawaii International Conference on System Sciences - 2005, 1-8. Retrieved from https://litmedmod.ca/sites/default/files/pdf/askehave_2005_multimodalite_genres.pdf

Askehave, I., \& Nielsen, A. E. (2005b). Digital genres: A challenge to traditional genre theory. Information Technology \& People, $18(2)$, 120-141. https://doi.org/10.1108/09593840510601504

Bell, A. (1991). Language of news media. Blackwell.

Bhatia, V. K. (2005). Generic patterns in promotional discourse. In H. Halmari, \& T. Virtanen (Eds.), Persuasion across genres: A linguistic approach (pp. 213-228). Benjamins.

Bolaños Medina, A., Rodríguez Medina, M. J., Bolaños Medina, L., \& Losada García, L. (2005). Analysing digital genres: Function and functionality in corporate websites of computer hardware. Ibérica, 9, 123-147.

Catenaccio, P. (2007a). Because crisis happens: Analysing the implicit in Parmalat's crisis press releases. ILCEA, 9, 153-170. https://doi.org/10.4000/ilcea.716

Catenaccio, P. (2007b). Constructing identities in the fashion industry: Building brand and customer image through press releases. In G. Garzone, \& C. Ilie (Eds.), The use of English in institutional and business settings: An intercultural perspective (pp. 31-56). Peter Lang.

Catenaccio, P. (2007c). New(s) genre and discursive identity: The changing face of the press release in the age of the Internet. In G. Garzone, G. Poncini, \& P. Catenaccio (Eds.), Multimodality in corporate communication: Web genres and discursive identity (pp. 55-72). Franco Angeli.

Catenaccio, P. (2008). Press releases as a hybrid genre: Addressing the informative/promotional conundrum. Pragmatics, 18(1), 9-31. https://doi.org/10.1075/prag.18.1.02cat

Cook, G. (2001). The discourse of advertising. Routledge.

Crowston, K., \& Williams, M. (2000). Reproduced and emergent genres of communication on the World-Wide Web. The Information Society, 16, 201-215. https://doi.org/10.1109/HICSS.1997.665482

Crystal, D. (2001). Language and the Internet. Cambridge University Press.

Desnica, M. (2018). The "consumption news brief": Semiotics of a press genre between information and promotion. Communication \& Languages, 198(4), 55-70. https://doi.org/10.3917/comla1.198.0055 
Dor, D. (2003). On newspaper headlines as relevance optimizers. Journal of Pragmatics, 35, 695-721. https://doi.org/10.1016/S0378-2166(02)00134-0

Ensink, T., \& Sauer, C. (2003). Social-functional and cognitive approaches to discourse interpretation: The role of frame and perspective. In T. Ensink, \& C. Sauer (Eds.), Framing and perspectivising in discourse (pp. 1-21). Benjamins.

Erjavec, K. (2004). Beyond advertising and journalism: Hybrid promotional news discourse. Discourse \& Society, 15, 553-578. https://doi.org/10.1177/0957926504045032

Finnemann, N. O. (2017). Hypertext configurations: Genres in networked digital media. Journal of the Association for Information Science \& Technology, 68(4), 845-854. https://doi.org/10.1002/asi.23709

Ifantidou, E. (2009). Newspaper headlines and relevance: Ad hoc concepts in ad hoc contexts. Journal of Pragmatics, 41, 699-720. https://doi.org/10.1016/j.pragma.2008.10.016

Ivantsiv, 0. (2018). Metaphorical modelling in the case of cosmetic companies' image development. Topics in Linguistics, 19(1), 82-92. https://doi.org/10.2478/topling2018-0006

Jacobs, G. (1999a). Preformulating the news: An analysis of the metapragmatics of press releases. Benjamins.

Jacobs, G. (1999b). Self-reference in press releases. Journal of Pragmatics, 31(2), 219-242. https://doi.org/10.1016/S0378-2166(98)00077-0

Jacobs, G. (2003). Reporting annual results: A single-case analysis. In T. Ensink, \& C. Sauer (Eds.), Framing and perspectivising in discourse (pp. 91-107). Benjamins.

Jacobs, G. (2014). Press releases. In K. Schneider, \& A. Barron (Eds.), Pragmatics of discourse (pp. 583-599). Mouton de Gruyter.

Jewitt, C. (2013). Multimodal methods for researching digital technologies. In S. Price, C. Jewitt, \& B. Brown (Eds.), The SAGE handbook of digital technology research (pp. 250-265). Sage.

Kress, G., \& van Leeuwen, T. (1996). Reading images: The grammar of visual design. Routledge.

Lassen, I. (2006). Is the press release a genre? A study of form and content. Discourse Studies, 8(4), 503-530. https://doi.org/10.1177/1461445606061875

Machin, D., \& van Leeuwen, T. (2007). Global media discourse: A critical introduction. Routledge.

Malekova, D. (2013). Self-reference in the leads of institutional press releases. Brno Studies in English, 39(1), 41-58.

McLaren, Y., \& Gurău, C. (2005). Characterising the genre of the corporate press release. LSP and Professional Communication, 5(1), 10-30.

Schneider, K. (2000). The emergence and development of headlines in British newspapers. In F. Ungerer (Ed.), English media texts past and present: Language and textual structure (pp. 45-66). Benjamins.

Skorczynska, H. (2016). A comparative study of keywords in English-language corporate press releases from European companies: Insights into discursive practices. Discourse and Interaction, 9(1), 49-64. https://doi.org/10.5817/DI2016-1-49

Skorczynska, H. (2020). "We are prepared to play our part ...": A case study of the use of first-person references in e-releases from two oil companies. Journal of Pragmatics, 155, 1-14. https://doi.org/10.1016/j.pragma.2019.09.013

Sleurs, K., \& Jacobs, G. (2005). Beyond preformulation: An ethnographic perspective on press releases. Journal of Pragmatics, 37(8), 1251-1273. https://doi.org/10.1016/j.pragma.2004.11.007 
Sleurs, K., Jacobs, G., \& van Waes, L. (2003). Constructing press releases, constructing quotations: A case study. Journal of Sociolinguistics, 7(2), 192-212. https://doi.org/10.1111/1467-9481.00219

Strobbe, I., \& Jacobs, G. (2005). E-releases: A view from linguistic pragmatics. Public Relations Review, 31(2), 289-291. https://doi.org/10.1016/j.pubrev.2005.02.009

Swales, J. M. (1990). Genre analysis: English in academic and research settings. Cambridge University Press.

Swales, J. M. (2019). The futures of EAP genre studies: A personal viewpoint. Journal of English for Academic Purposes, 38, 75-82. https://doi.org/10.1016/j.jeap.2019.01.003

Thaeler, J. M. (2009). I need a killer press release: Now what???: A guide to online PR. Happy About.

Vorvoreanu, M. (2008). ROI of online press releases. Journal of New Communications Research, 3(1), 92-99.

Wales, K. (2001). A dictionary of stylistics (2nd ed.). Pearson Education.

Xia, S. A. (2020). Genre analysis in the digital era: Developments and challenges. ESP Today, 8(1), 141-159. https://doi.org/10.18485/esptoday.2020.8.1.7

Yakhontova, T. (2002a). 'Selling or telling'? The issue of cultural variation in research genres. In J. Flowerdew (Ed.), Academic discourse (pp. 216-232). Longman.

Yakhontova, T. (2002b). Titles of conference presentations abstracts: A cross-cultural perspective. In E. Ventola, C. Shalom, \& S. Thompson (Eds.), The language of conferencing (pp. 277-300). Peter Lang.

Yakhontova, T. (2019). "The authors have wasted their time...": Genre features and language of anonymous peer reviews. Topics in Linguistics, 20(2), 67-89. https://doi.org/10.2478/topling-2019-0010

TATYANA YAKHONTOVA is Professor of English for Specific Purposes and Linguistics at the Ivan Franko National University of Lviv (Ukraine). Her research interests include genre theory and analysis, genre-based pedagogy, contrastive rhetoric and writing instruction. She has published articles in English for Specific Purposes, Journal of English for Academic Purposes, JAC: A Journal of Composition Theory, Topics in Linguistics, and Journal of Korean Medical Science (Editing, Writing \& Publishing section). She has also contributed chapters to the books published by Mouton de Gruyter, Longman, Peter Lang, Cambridge Scholars, Springer, and Palgrave Macmillan.

ORYSLAVA IVANTSIV is Associate Professor at the Faculty of Foreign Languages, Ternopil Volodymyr Hnatiuk National Pedagogical University (Ukraine). She earned her PhD in English Language and Linguistics from the Ivan Franko National University of Lviv. Her research and teaching interests include ESP, discourse analysis, pragmatics, cognitive linguistics, genre analysis and translation studies. She has published numerous academic papers in national and international journals. 